\title{
Revealing the timing of ocean stratification using remotely-sensed ocean fronts
}

\author{
Peter I. Miller ${ }^{1}$, Benjamin R. Loveday \\ Remote Sensing Group, Plymouth Marine Laboratory, \\ Prospect Place, Plymouth PL1 3DH, UK.
}

\begin{abstract}
Stratification is of critical importance to the circulation, mixing and productivity of the ocean, and is expected to be modified by climate change. Stratification is also understood to affect the surface aggregation of pelagic fish and hence the foraging behaviour and distribution of their predators such as seabirds and cetaceans. Hence it would be prudent to monitor the stratification of the global ocean, though this is currently only possible using in situ sampling, profiling buoys or underwater autonomous vehicles. Earth observation (EO) sensors cannot directly detect stratification, but can observe surface features related to the presence of stratification, for example shelf-sea fronts that separate tidally-mixed water from seasonally stratified water. This paper describes a novel algorithm that accumulates evidence for stratification from a sequence of oceanic front maps, and discusses preliminary results in comparison with in situ data and simulations from 3D hydrodynamic models. In certain regions, this method can reveal the timing of the seasonal onset and breakdown of stratification.
\end{abstract}

Keywords: oceanic fronts; remote sensing; stratification; sea-surface temperature; ocean colour.

\section{INTRODUCTION}

Stratification is of critical importance to the mixing and productivity of the ocean, though currently it can only be measured using in situ sampling, profiling buoys or underwater autonomous vehicles. Stratification affects the surface aggregation of pelagic fish and hence the foraging habitat of their predators such as seabirds and cetaceans. Satellite Earth observation (EO) sensors cannot directly detect stratification, but can observe surface features related to the presence of stratification, for example shelf-sea fronts that separate tidally-mixed water from seasonally stratified water (Figure 1). We present a novel algorithm that accumulates evidence for stratification from a sequence of oceanic front maps, and in certain regions can reveal the timing of the onset and breakdown of stratification.

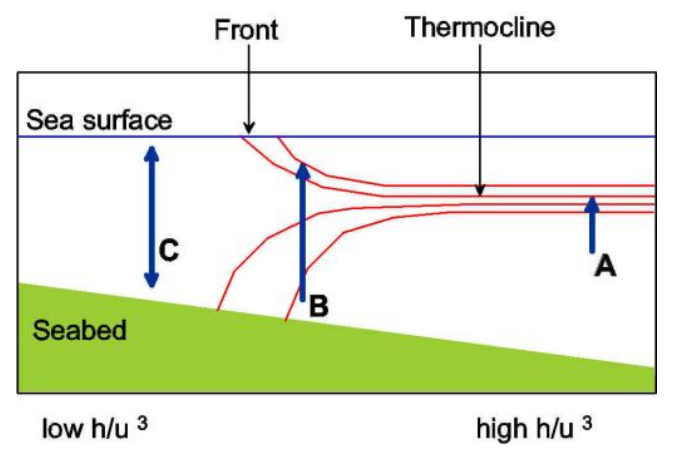

Figure 1. Stratification and a tidal mixing front (from [1]).

\section{METHODS}

This research is based on the composite front map approach, which is to combine the location, strength and persistence of all fronts detected on EO sea-surface temperature (SST) or ocean colour data over several days into a single map,

\footnotetext{
${ }^{1}$ E-mail: pim@pml.ac.uk
} 


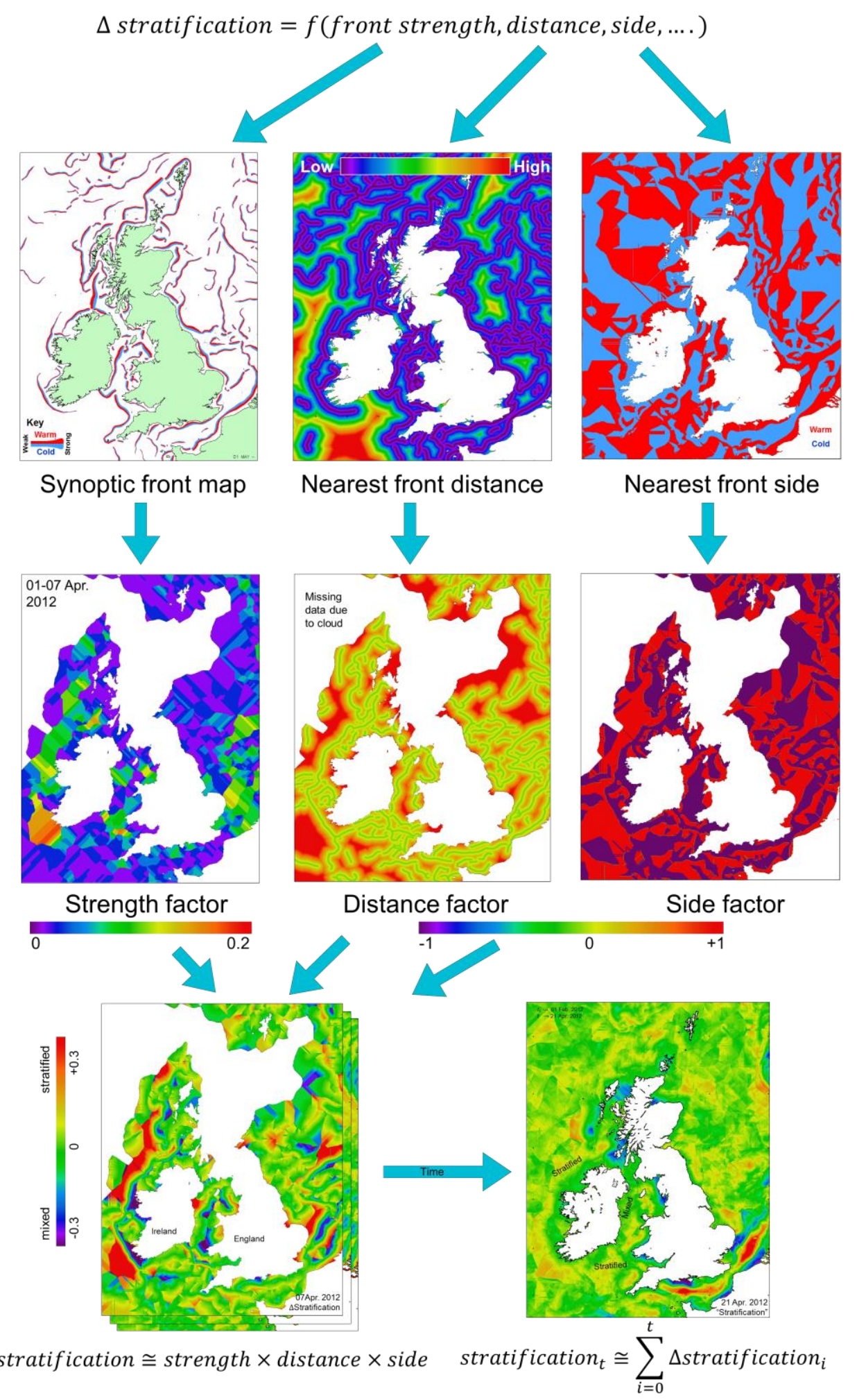

Figure 2. Schematic diagram of the proposed method to estimate the timing of shelf-sea stratification using remotelysensed ocean fronts.

improving interpretation of dynamic mesoscale structures [2]. These techniques are robust and generic, and have been applied to many studies of physical oceanography, and marine animal distribution. We derived ocean front metrics from $1 \mathrm{~km}$ resolution AVHRR sea-surface temperature (SST) daily scenes from 2010 to 2012 [3]: $F_{\text {syn }}$ - synoptic front map, shows the strength of major fronts based on a novel clustering algorithm; $F_{\text {dist }}$ - the distance from any location to the closest simplified front; and $F_{\text {side }}$ - whether a pixel is on the warm or cold side of the front. In this study the metrics are each based upon 7 days of thermal front observations.

The offshore side of tidal mixing front will become more stratified, and hence warmer at the surface, the longer the front persists. Hence we propose that the strength of stratification will change according to the front gradient strength, 
which indicates the cross-front difference in SST; front distance, as water further away from the tidal mixing will become more stratified; and front side.

We calculated three spatial factor maps needed for the function to estimate the change in stratification (Figure 2). The strength factor indicates for each pixel the gradient of the closest major front. The distance and side factors are simply the $F_{\text {dist }}$ and $F_{\text {side }}$ metrics scaled between -1 and +1 .

Making a further simplification, we parameterise the change in stratification as the product of these three factors. This map is of limited value on its own, but when considered over a time-series, we can estimate the degree of stratification as the summation of all preceding $\Delta$ stratification maps.

\section{INITIAL RESULTS}

The example $\Delta$ stratification map for a week in April 2012 demonstrates the intended behaviour of the algorithm (Figure 2 bottom left), where the front southwest of Ireland indicates stratification increasing further offshore (red), and decreasing further inshore (blue-purple, greater tidal mixing).

The time-summed EO stratification map for 07 Jul. 2012 shows how the evidence for stratification is combined and gradually converges (Figure 2 bottom right). As the tidal mixing fronts change in strength and location through the seasons, the result has fewer extreme values. The persistent fronts around the continental shelf of Ireland and smaller Scottish islands have resulted in a higher likelihood of mixing inshore, and a stratified band offshore. This concurs with our knowledge of the hydrography in this region.

\section{VALIDATING APPROACH USING MODEL}

We now wish to validate the EO stratification timing against a high resolution $(1.8 \mathrm{~km}) 3 \mathrm{D}$ ocean model: the Atlantic Margin Model (AMM60), developed within the NERC FASTNEt project [4] (Figure 3a). This model has the NEMO framework, with 51 sigma levels and full surface forcing. Figure 3b shows the modelled mixed layer depth (MLD) for 17 Apr. 2012, almost the same date as the EO stratification map (Figure 2 bottom right). The MLD indicates higher values where there is mixing deeper into the water column, and lower values where stratification restricts mixing closer to the surface. We can observe visually that certain regions agree between the EO surface estimate of mixing/stratification and the model MLD. However, there are clearly limitations with the current simple formulation of the EO stratification function. We are currently developing a procedure for quantitative comparison in order to assess improvements to the approach.

\section{CONCLUSIONS AND FUTURE WORK}

We have demonstrated promising initial results from a novel approach to inferring the timing of stratification, a subsurface process, from a time-sequence of ocean-surface front maps. Future work will be focussed on relating this new remotely sensed metric to marine predator distributions, as a further tool for marine planning and conservation. For example, gannet dive locations from GPS tags (Figure 4) may be more associated with stratified conditions than front locations [5].

To achieve this aim we first need to discriminate tidal-mixing fronts from other fronts, and incorporate a physical basis (buoyancy, Richardson number) and other EO parameters into the stratification function. 


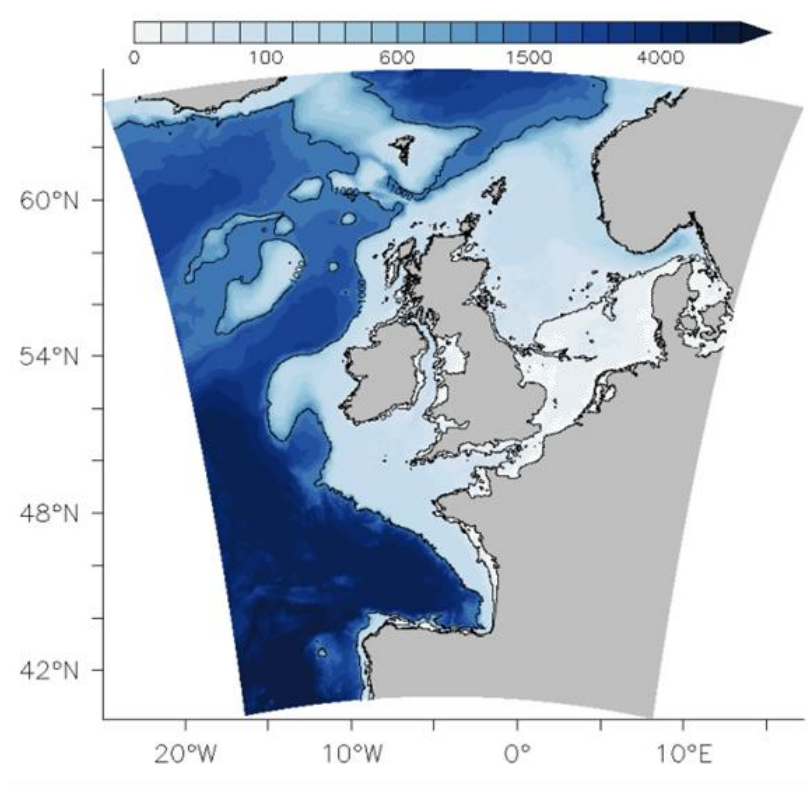

a

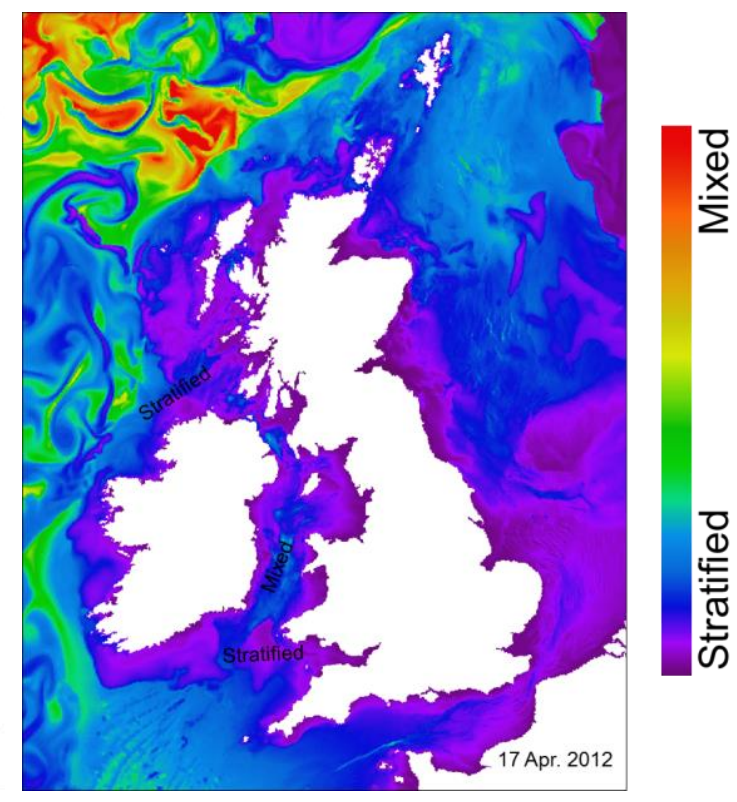

$\mathrm{b}$

Figure 3. (a) AMM60 model domain. (b) Modelled mixed layer depth.

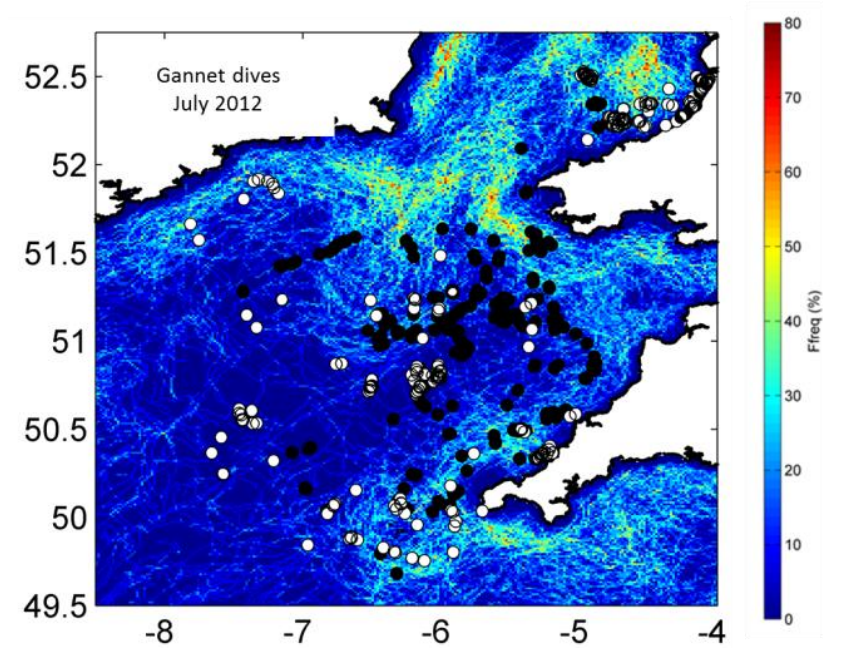

Figure 4. Tagged gannet foraging dives (black dots: male, white: female) overlaid on thermal front frequency

\section{ACKNOWLEDGEMENTS}

This research was funded by the NERC Fluxes Across Sloping Topography of the North East Atlantic (FASTNEt) project, with data processed by NERC Earth Observation Data Acquisition and Analysis Service (NEODAAS).

\section{REFERENCES}

[1] J. Sharples, and J. H. Simpson, [Shelf Sea and Shelf Slope Fronts] Academic Press, Oxford (2009).

[2] P. I. Miller, "Composite front maps for improved visibility of dynamic sea-surface features on cloudy SeaWiFS and AVHRR data," Journal of Marine Systems, 78(3), 327-336 (2009).

[3] P. I. Miller, K. L. Scales, S. N. Ingram et al., "Basking sharks and oceanographic fronts: quantifying associations in the north-east Atlantic," Functional Ecology, 29(8), 1099-1109 (2015).

[4] K. Guihou, J. Harle, J. Holt et al., "High-resolution modelling of ocean-shelf exchange: assessment of a 1/60th NEMO configuration of the Atlantic margin (AMM60)," EGU General Assembly 2015, (2015).

[5] S. L. Cox, M. J. Witt, C. B. Embling et al., "Temporal patterns in habitat use by small cetaceans at an oceanographically dynamic marine renewables test site in the Celtic Sea,” Deep Sea Research Part II: Topical Studies in Oceanography, 141, 178-190 (2017). 